\title{
Aloe Vera Gel as a Traditional and Complementary Method for Chronic Skin Burn: A Case Report
}

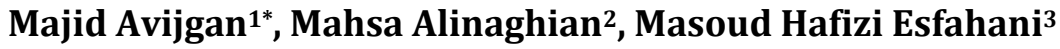 \\ ${ }^{1}$ Departments of a Traditional Persian Medicine and Infectious Diseases, Isfahan University of Medical Sciences, Isfahan, Iran \\ ${ }^{2}$ Department of Infectious Diseases, Isfahan University of Medical Sciences, Isfahan, Iran \\ ${ }^{3}$ Department of Infectious Diseases, Shar-e-kord University of Medical Sciences, Shahr-e-Kord, Iran \\ Email: *avijgan@yahoo.com, mahsa_alinaghian@yahoo.com, Massoud_hafizi@yahoo.com
}

How to cite this paper: Avijgan, M., Alinaghian, M. and Esfahani, M.H. (2017) Aloe Vera Gel as a Traditional and Complementary Method for Chronic Skin Burn: A Case Report. Advances in Infectious Diseases, 7, 19-25.

https://doi.org/10.4236/aid.2017.71003

Received: February 13, 2017

Accepted: March 19, 2017

Published: March 22, 2017

Copyright $\odot 2017$ by authors and Scientific Research Publishing Inc. This work is licensed under the Creative Commons Attribution International License (CC BY 4.0).

http://creativecommons.org/licenses/by/4.0/

\begin{abstract}
Burn victims around the world are forced to a life of long lasting morbidity and high mortality rate. Although physiotherapy and occupational therapy subside the painful side of morbidity after severe skin burns, patients are under huge financial pressure in order to return to health. Various treatment plans are used for severe burn injuries. Aloe Vera Gel is introduced recently as an alternative management for burn injuries through betterment of granulation tissue formation and epithelialization. Moreover, numerous studies reported Aloe Vera healing effect on chronic wounds by manipulating collagen layout. This study aims to present the therapeutic impact of Aloe Vera Gel on chronic skin burns of a 17 -year-old female who was referred to our department because of rejected skin graft.
\end{abstract}

\section{Keywords}

Aloe Vera Gel, Burn, Complementary Medicine, Traditional Medicine

\section{Introduction}

Thermal or fire burns are universal household injuries commonly reported among various ages. Disaster occurs when burn leaves disability on its path besides affecting patients' mental, psychological, and physiological conditions [1]. Thermal injuries were ranked fourth in all injuries which were reported among 11 million victims globally as well as posing high risk of septicemia, hypovolemic shock, and mortality. Burn injuries are also among the leading causes of disability-adjusted life even after years of rehabilitation. Regarding gender, death as a result of burn injures was higher among boys. However, female victims between 
15 - 19 experienced higher death rate in developing and underdeveloped countries [2]. Thermal injuries mostly involve victims from ages of 20 to 30 in Iran [3] as well as imposing millions of dollars to health system yearly [4].

Aloe Vera products are known for their cosmetic use [5] besides having antimicrobial, anti-inflammatory, moisturizing effects [6] [7], ceasing neurodegeneration and cardiovascular illness [8] [9], and immunomodulatory action [7]. Aloe Vera plant is harvested in some areas around the world like eastern European, Africa [10], and south regions of Iran [11]. Interestingly, the healing process of chronic bed sores is improved by topical Aloe Vera Gel [6] [11] [12]. After several in vitro studies of Aloe Vera Gel, Avijgan (2004) reported one of the earliest in vivo experiences of the healing effect of Aloe Vera Gel in humans [13]. Regarding Aloe Vera healing effect on skin, it induces collagen cross linking and hyaluronic acid and dermatan sulfate production through stimulation of growth factor receptors of fibroblast cells [12] which will result in wound contraction as well as improving granulation tissue formation [1]. Moreover, corneal re-epithelialization was reported as a consequence of topical Aloe Vera Gel [14].

Hereon, this case study reports the healing impact of topical Aloe Vera Gel on the burn injuries of a 17-year-old victim who was referred to our department because of the rejected skin graft as well as the chronicity state of skin injuries after the fire burn.

\section{Case Presentation}

A 17-year-old female burn victim was referred to our Department of Infectious Diseases with dyspnea. Previously, she had experienced 30\% - 40\% second degree fire related skin burns in the upper limbs, neck, face, ears, scalp, eyelids, and anterior thorax 40 days before her admission in our facility (Figure 1). She had

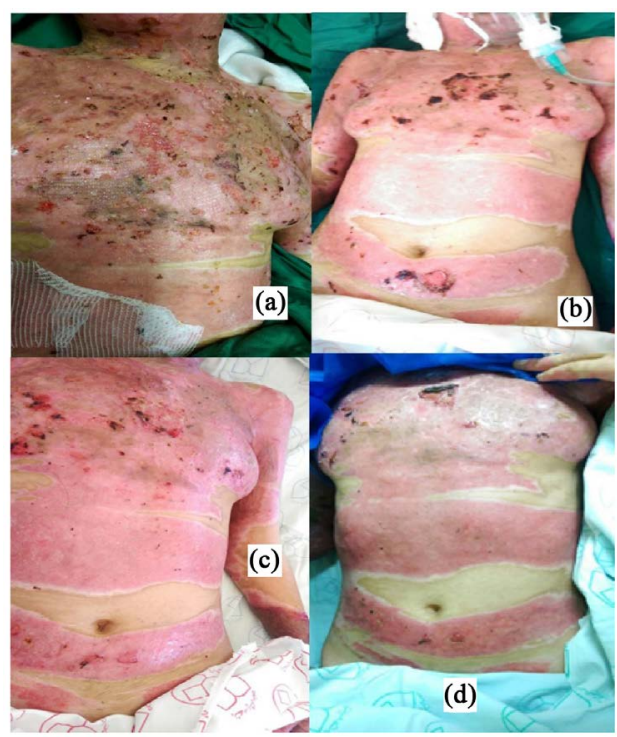

Figure 1. (a) Presentation of chronic skin burns and rejected skin graft on her chest and sternum at the time of admission; (b) The skin burns 13 Days after Aloe Vera application; (c) The granulation tissue formation at the 18th day of treatment; (d) Complete healing of wounds and starting of epithelialization 21 days after Aloe Vera Gel treatment. 
been admitted in another burn treatment unit and the skin graft procedure on the anterior thorax had been done by a plastic surgeon by harvesting healthy skin from her thighs, but the graft had been rejected after 5 days (Figure 1). However, she was admitted in our facility due to chronic unhealed skin injuries and skin graft failure. The skin injuries had serous secretion which was dressed by gas Vaseline. During physical exam she had tachypnea, dyspnea, fever, unstable vital sign with fluctuating $\mathrm{O}_{2}$ Saturation level, mild stridor, and bilateral crackle sounds at the base of both lungs. In relation to our primary observation, wounds in pre-sternal area, ears, and pre-umbilicus were crusted. The rest of the skin lesions were warm, a little tender, and erythematic with serous secretions (Figure 1). Simultaneously, chest X-ray showed bilateral haziness and alveolar infiltration which raised the suspicious of pneumonia (Figure 2). Thorax MDCT scan revealed patchy ground glass infiltrations in right upper lobes and consolidation in superior segments of both lower lobes recommending bacterial pneumonia while no mediastinal or hilar lymphadenopathy and pulmonary thromboembolism (PTE) were detected. Neck MDCT scan showed narrowing of tracheal lumen with approximate length of $20 \mathrm{~mm}$ at the level of thoracic inlet, fine linear tracheal calcification, and normal laryngeal structure. As a matter of fact, she suffered from a respiratory distress due to burn injury of trachea which resulted in tracheal stenosis and fibrosis. Laboratory data reveals the following findings: ESR ( $64 \mathrm{~mm} \rightarrow 41 \mathrm{~mm} \rightarrow 37 \mathrm{~mm} \rightarrow 30 \mathrm{~mm}$ (normal: 0 - 29) per first hour), CRP (14 $\rightarrow 15$ (normal: 0 - 3) $\mathrm{mg} / \mathrm{dl}$ ), Procalcitonin $(0.3 \rightarrow 0.2$ (normal < $0.15) \mathrm{mcg} / \mathrm{l}), \mathrm{Cr}(0.5$ (normal: 0.6 - 1.2) mg/dl), WBC $(29,200 \rightarrow 22,200 \rightarrow 12,600$ $\rightarrow 8500 \rightarrow 6400$ (normal: $4500-10,000) / \mathrm{mcl}$ ), $\mathrm{Hb}(8.9 \rightarrow 9.2 \rightarrow 10.3 \rightarrow 10.9$ (normal: 12 - 15.9) gr/dl), Platelets $(666,000 \rightarrow 566,000 \rightarrow 464,000 \rightarrow 334,000$ (normal: $150,000-450,000) / \mathrm{mcl}$ ). Except increased ESR, WBC and decreased Hb, other are in the normal ranges.

Immediately, she was transferred to ICU department because of her unstable condition after primary oxygen therapy and fluid resuscitation. Based on her primary lab data and imaging findings, bacterial pneumonia was treated by administering IV antibiotics such as Meropenem, Vancomycin, Levofloxacin. Antibiotic therapy was discontinued after 14 days of her admission in the ICU and

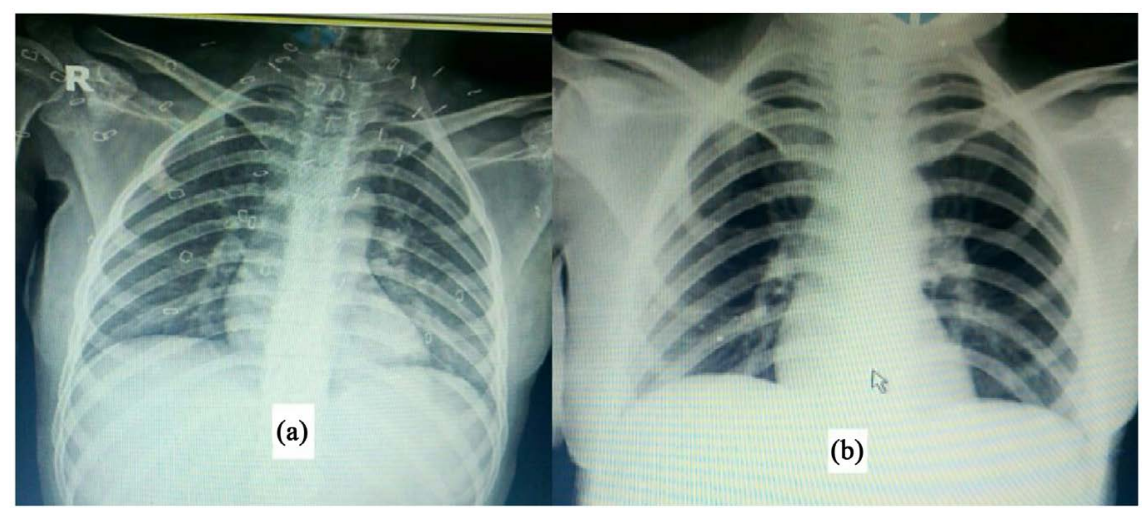

Figure 2. (a) CXR showing pneumonia at the admission; (b) Follow-up CXR 2 weeks later. 
follow-up chest X-ray (Figure 2) revealed no pathological findings of pneumonia as well as having no respiratory complains.

Informed consent form was taken and the advantages and disadvantages of the Aloe Vera Gel were explained thoroughly for the patient before starting the treatment.

Regarding her skin wounds, Aloe Vera Gel was applied every 12 hours instead of Gas Vaseline dressing. In order to prepare our Aloe Vera Gel, Aloe Vera mucilage and lubricant gel (Lubricant gel produced by Iran, treatment instruments factory, Salem brand) were mixed with the ratio of five to one like our previous studies [12] [15]. First, the injured area was washed by normal saline drips. Then, it was covered by pieces of Aloe Vera Gel in a fashion that covered the most possible area of the injuries. When the area dried after 30 minutes, a single layer dry dressing was done in sterilized fashion. This type of wound dressing with Aloe Vera Gel was done on all of the burned area for 21 days continually. Skin healing process started by formation of granulation tissue and epithelialization of the wounds (Figure 1 and Figure 3). However, new skin was tough and tense in injured areas such as the neck and elbow after 21 days. But, no sign of skin infection was detected during treatment. Moreover, she reported no topical side effects of Aloe Vera Gel like allergic reaction and itching. Despite ceasing wound serous secretions, skin fibrosis had led to increased skin tension and joint stricture in the upper limbs although proper physiotherapy was started at the time of patient's admission in the ICU after 40 days of Aloe Vera Gel treatment. Additional plastic surgeries were done to release skin tension and ease upper limbs joints range of motion.

In other words, there is comparative study of before-after type, in a case of fire burnt in whom starting the AVG is accompanied with repairing process of lesion.
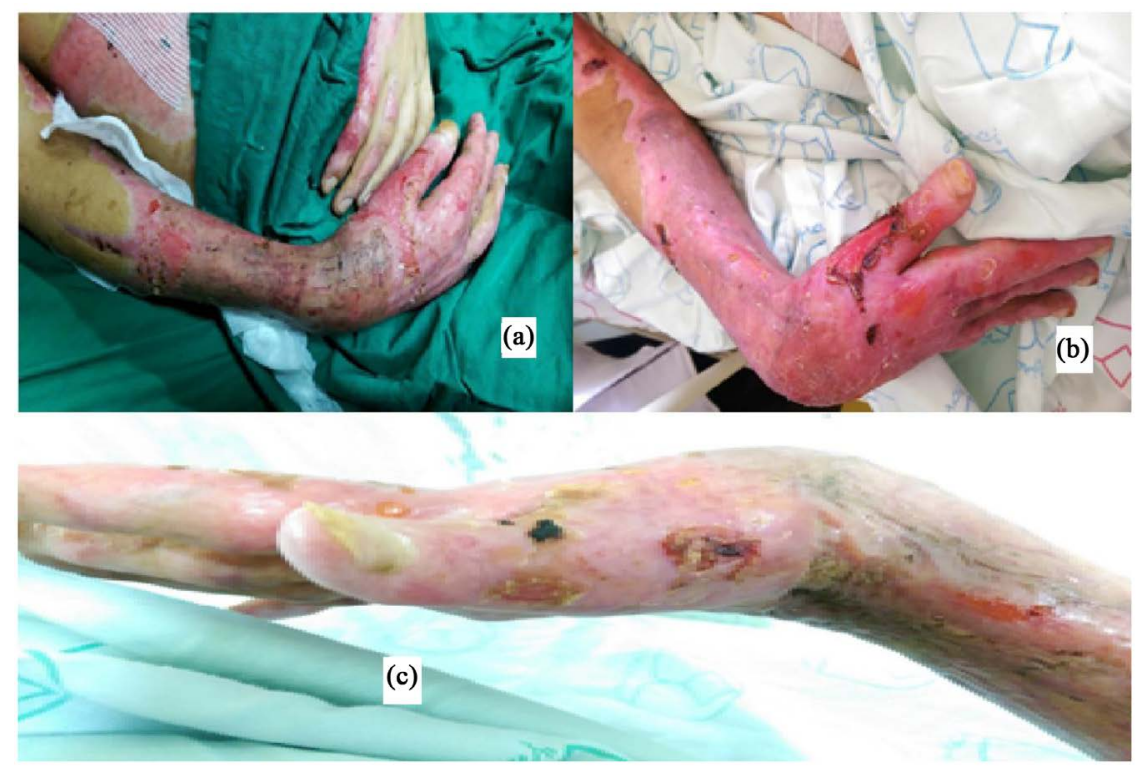

Figure 3. (a) Hand skin injuries at the admission; (b) lesions after 14 days of treatment; (c) The granulation tissue formation and epithelialization of the lesions at the 21 th day. 


\section{Discussion}

This is a comparative study of before-after type, in a case of fire burn in whom starting the AVG is accompanied with promotion of repairing process of lesion.

Fire related skin injuries are at the top of list causing DALYs lost in low income countries. Impaired economical condition has a direct relationship with higher mortality and morbidity rate. Burn injuries are now a major health issue after surveying the challenges posed by fire related skin burns globally. It is a common belief that prevention of burn injuries is prior to finding the best treatment afterwards [2] [3] [4]. One study in Iran has claimed that flammable substances were mostly responsible for burn injuries. Furthermore, burn injuries were more common in urban areas and patients were under 30 at the time of incidence. As a matter of fact, it is well-known that education of safety measures has a fundamental role in prevention of thermal injuries [3]. Avijgan M. reported one of the early case reports of Aloe Vera Gel healing impact on chronic ulcer [13]. In addition, comparative study on 60 patients of chronic skin wounds conducted by Avijgan M. et al. claimed that Aloe Vera Gel reduced the duration of wound healing process and hospitalization by half [15].

Aloe Vera is a traditional medicinal plant that is harvest in south area of Iran and other regions [13]. Since 1930, Aloe Vera Gel has been used in clinical practices. Before that, analysis of Aloe Vera Gel revealed that it has glucomannans, acemmanan, carboxypeptidase, salicylates, and thromboxane inhibitors. Aloe Vera Gel inhibits skin ischemia through ceasing thromboxane production. It affects immune system by increasing macrophage capacity and stimulates dendritic cells maturation as well as its anti-inflammatory impact [10] [13] [16] [17] [18]. A case study reported the healing impact of Aloe Vera Gel on deep vein thrombosis ulcer on her leg. Although surgical and antibiotic management had been unsuccessful, after 58 days of topical Aloe Vera Gel healing occurred as her last resort [13]. Another study on 19 cases of chronic skin wounds demonstrated that Aloe Vera Gel reduced erythema, tenderness, and secretion which showed its anti-inflammatory and antibacterial roles. As a matter of fact, wound healing rate was increased as well as having cost effective [11]. Goudarzi et al. expressed that specific concentration of Aloe Vera Gel had antibacterial effect on multidrug resistant (MDR) Pseudomonas aeruginosa separated from burn injuries infection [7]. Regarding one case report in our literature review, Aloe Vera Gel had sometimes unsuccessful outcome on the healing process of chronic skin injuries after multiple trauma. By considering one remedy of Traditional Persian Medicine administering (solution of Potassium permanganate) as a topical solution in stopped healing of skin ulcer by Aloe Vera Gel ended in complete wound healing [19]. Besides that Aloe Vera Gel induces angiogenesis and relieves vasodilation in burn wounds. In contrast to silver sulfadiazine, Aloe Vera Gel was more effective and a proper choice of treatment financially based on one clinical trial [18]. Although the effect of Aloe Vera Gel has been approved (since one hundred years ago) for radiation ulcers after radiotherapy, but few literatures have reported the effect of Aloe Vera Gel on fire burn injuries [20] [21] [22]. 
Despite the fact that our patient suffered from chronic skin burns and skin graft rejection, we observed a decrease in erythema and wound secretion as well as developing no skin infections after 3 weeks of treatment with Aloe Vera Gel. In other words, rapid developing granulation tissue and no experience of allergic and or even infection reaction may conclude that in comparison to time before the usage of Aloe Vera Gel, after usage of Aloe Vera Gel has a significant, rapid, healing effect and promotes repairing process.

Although there are some cases of Aloe Vera Gel failure on skin healing process, which can be resolved by adding a topical astringing solution like Potassium permanganate regarding Traditional Persian Medicine but this issue did not happened.

We suggest further clinical researches are necessary to investigate their supplementary healing role. Based on our case observation and review of literature, Aloe Vera Gel is a cheap and effective alternative approach to chronic unhealed burn wounds. This study may be one of the first case reports of the Aloe Vera Gel healing impact on burn injuries and may be considered as a fast, cheap and rapid effect of replacement therapy instead of surgical intervention.

\section{References}

[1] Abdel Hamid, A.A.M. and Soliman, M.F.M. (2015) Effect of Topical Aloe vera on the Process of Healing of Full-Thickness Skin Burn: A Histological and Immunohistochemical Study. Journal of Histology and Histopathology, 2, 3. https://doi.org/10.7243/2055-091X-2-3

[2] Peck, M.D. (2011) Epidemiology of Burns throughout the World. Part I: Distribution and Risk Factors. Burns, 37, 1087-1100. https://doi.org/10.1016/j.burns.2011.06.005

[3] Goodarzi, M., Reisi-Dehkordi, N., Daryabeigi, R. and Zargham-Boroujeni, A. (2014) An Epidemiologic Study of Burns: Standards of Care and Patients' Outcomes. Iranian Journal of Nursing and Midwifery Research, 19, 385-389.

[4] Karimi, H., Motevalian, S.A., Momeni, M. and Ghadarjani, M. (2015) Financial Burden of Burn Injuries in Iran: A Report from the Burn Registry Program. Annals of Burns and Fire Disasters, 28, 310-314.

[5] Surjushe, A., Vasani, R. and Saple, D.G. (2008) Aloe vera: A Short Review. Indian Journal of Dermatology, 53, 163-166. https://doi.org/10.4103/0019-5154.44785

[6] Reynolds, T. and Dweck, A.C. (1999) Aloe vera Leaf Gel: A Review Update. Journal of Ethnopharmacology, 68, 3-37.

[7] Goudarzi, M., Fazeli, M., Azad, M., Seyedjavadi, S.S. and Mousavi, R. (2015) Aloe vera Gel: Effective Therapeutic Agent against Multidrug-Resistant Pseudomonas aeruginosa Isolates Recovered from Burn Wound Infections. Chemotherapy Research and Practice, 2015, Article ID: 639806.

[8] Ehsani, M., Amin Marashi, M., Zabihi, E., Issazadeh, M. and Khafri, S. (2013) A Comparison between Antibacterial Activity of Propolis and Aloe vera on Enterococcus faecalis (an in Vitro Study). International Journal of Molecular and Cellular Medicine, 2, 110-116.

[9] Nejatzadeh-Barandozi, F. (2013) Antibacterial Activities and Antioxidant Capacity of Aloe vera. Organic and Medicinal Chemistry Letters, 3, 5. https://doi.org/10.1186/2191-2858-3-5 
[10] Radha, M.H. and Laxmipriya, N.P. (2015) Evaluation of Biological Properties and Clinical Effectiveness of Aloe vera: A Systematic Review. Journal of Traditional and Complementary Medicine, 5, 21-26.

[11] Avijgan, M. (2004) Aloe vera Gel as an Effective and Cheap Option for Treatment in Chronic Bed Sores. JGUMS, 13, 45-51.

[12] Avijgan, M. and Mirzadeh, F. (2011) Treatment of Delayed Healing of Chronic Ulcers Using Aloe vera (Sabr) Gel. JIITM, 2, 237-242.

[13] Avijgan, M. (2004) Phytotherapy: An Alternative Treatment for Non-Healing Ulcers. Journal of Wound Care, 13, 157-158. https://doi.org/10.12968/jowc.2004.13.4.26599

[14] Atiba, A., Wasfy, T., Abdo, W., Ghoneim, A., Kamal, T. and Shukry, M. (2015) Aloe vera Gel Facilitates Re-Epithelialization of Corneal Alkali Burn in Normal and Diabetic Rats. Clinical Ophthalmology, 9, 2019-2026.

[15] Avijgan, M., Kamran, A. and Abedini, A. (2016) Effectiveness of Aloe vera Gel in Chronic Ulcers in Comparison with Conventional Treatments. Iranian Journal of Medical Sciences, 41, S30.

[16] Avijgan, M. (2009) Healing Effect of ALoe Ver Gel, in Non Healed Ulcers. Asian Pacific Journal of Tropical Medicine, 2, 1-6.

[17] Renisheya Joy Jeba Malar, T., Johnson, M., Nancy Beaulah, S., Laju, R.S., Anupriya, G. and Renola Joy Jeba Ethal, T. (2012) Anti-Bacterial and Antifungal Activity of Aloe Vera Gel Extract. International Journal of Biomedical and Advance Research, 3, 184-187.

[18] Akhoondinasab, M.R., Akhoondinasab, M. and Saberi, M. (2014) Comparison of Healing Effect of Aloe vera Extract and Silver Sulfadiazine in Burn Injuries in Experimental Rat Model. World Journal of Plastic Surgery, 3, 29-34.

[19] Avijgan, M., Avijgan, M., Hakamifard, A. and Razavi, N. (2016) An Innovation for Retarded Healing Process of a Chronic Ulcer by Aloe vera Gel Treatment. Journal of Natural Remedies, 16, 45-51. https://doi.org/10.18311/jnr/2016/479

[20] Collins, C.E. and Collins, C. (1935) Roentgen Dermatitis Treated with Fresh Whole Leaf of Aloe vera. American Journal of Roentgen, 33, 396-397.

[21] Rattner, H. (1936) Roentgen Ray Dermatitis with Ulcers. Archives of Dermatology and Syphilology, 33, 593-594.

[22] Visuthikosol, V., Chowchuen, B., Sukwanarat, Y., Sriurairatana, S. and Boonpucknavig, V. (1995) Effect of Aloe vera Gel to Healing of Burn Wound: A Clinical and Histologic Study. Journal of the Medical Association of Thailand, 78, 403-409. 
Submit or recommend next manuscript to SCIRP and we will provide best service for you:

Accepting pre-submission inquiries through Email, Facebook, LinkedIn, Twitter, etc. A wide selection of journals (inclusive of 9 subjects, more than 200 journals)

Providing 24-hour high-quality service

User-friendly online submission system

Fair and swift peer-review system

Efficient typesetting and proofreading procedure

Display of the result of downloads and visits, as well as the number of cited articles Maximum dissemination of your research work

Submit your manuscript at: http://papersubmission.scirp.org/

Or contact aid@scirp.org 